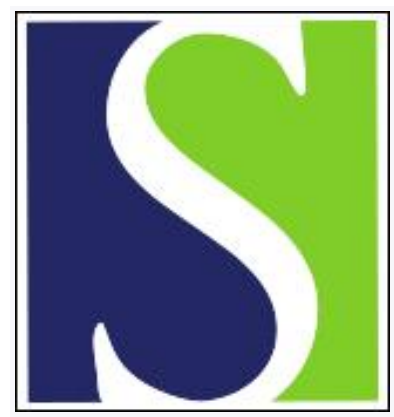

Scand J Work Environ Health 2017;43(4):326-336

https://doi.org/10.5271/sjweh.3649

Published online: 30 May 2017, Issue date: 01 Jul 2017

Predicting working beyond retirement in the Netherlands: an interdisciplinary approach involving occupational epidemiology and economics

by Scharn M, van der Beek AJ, Huisman M, de Wind A, Lindeboom M, Elbers CTM, Geuskens GA, Boot CRL

No study so far has combined detailed register-based socioeconomic information with in-depth information on demographics, health, social environment and work characteristics in one study. This study provides indications that workers who work beyond retirement can be identified from the total population of older workers by health, work and social environmental characteristics rather than socioeconomic or demographic characteristics.

Affiliation: VU University Medical Center, Department of Public and Occupational Health, Van der Boechorststraat 7, 1081 BT Amsterdam, the Netherlands. crl.boot@vumc.nl

Refers to the following texts of the Journal: 2005;31(6):438-449 2015;41(1):24-35

The following articles refer to this text: 2021;47(1):15-21; 2021;47(1):1-3

Key terms: ageing; economics; interdisciplinary approach; longitudinal study; occupational epidemiology; prediction model; retirement; The Netherlands; worker

This article in PubMed: www.ncbi.nlm.nih.gov/pubmed/28560378

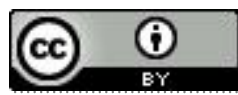




\title{
Predicting working beyond retirement in The Netherlands: an interdisciplinary approach involving occupational epidemiology and economics
}

\author{
by Micky Scharn, MSc, ${ }^{1}$ Allard J van der Beek, PhD, ${ }^{1,2}$ Martijn Huisman, PhD, ${ }^{3,4}$ Astrid de Wind, PhD, 1, 2, 6 \\ Maarten Lindeboom, PhD, ${ }^{5}$ Chris TM Elbers, PhD, ${ }^{5}$ Goedele A Geuskens, PhD, ${ }^{2,6}$ Cécile RL Boot, PhD ${ }^{1,2}$
}

\begin{abstract}
Scharn M, van der Beek AJ, Huisman M, de Wind A, Lindeboom M, Elbers CTM, Geuskens GA, Boot CRL. Predicting working beyond retirement in The Netherlands: an interdisciplinary approach involving occupational epidemiology and economics. Scand J Work Environ Health. 2017;43(4):326-336. doi:10.5271/sjweh.3649
\end{abstract}

\begin{abstract}
Objectives No study so far has combined register-based socioeconomic information with self-reported information on health, demographics, work characteristics, and the social environment. The aim of this study was to investigate whether socioeconomic, health, demographic, work characteristics and social environmental characteristics independently predict working beyond retirement.

Methods Questionnaire data from the Study on Transitions in Employment, Ability and Motivation were linked to data from Statistics Netherlands. A prediction model was built consisting of the following blocks: socioeconomic, health, demographic, work characteristics and the social environment. First, univariate analyses were performed $(\mathrm{P}<0.15)$, followed by correlations and logistic multivariate regression analyses with backward selection per block $(\mathrm{P}<0.15)$. All remaining factors were combined into one final model $(\mathrm{P}<0.05)$.

Results In the final model, only factors from the blocks health, work and social environmental characteristics remained. Better physical health, being intensively physically active for $>2$ days/week, higher body height, and working in healthcare predicted working beyond retirement. If respondents had a permanent contract or worked in handcraft, or had a partner that did not like them to work until the official retirement age, they were less likely to work beyond retirement.

Conclusion Health, work characteristics and social environment predicted working beyond retirement, but register-based socioeconomic and demographic characteristics did not independently predict working beyond retirement. This study shows that working beyond retirement is multifactorial.
\end{abstract}

Key terms ageing; longitudinal study; prediction model; worker.

A majority of the baby boom generation has reached the official retirement age and is being replaced by a smaller group of younger workers. This results in pressure on the social security system (1). Many governments are seeking changes in legislation of the social security system to encourage older workers to work longer $(2,3)$. For example, the statutory retirement age will gradually increase from 65 to 67 years in the Netherlands (3). A subgroup of workers continues working in some kind of paid employment after their early or statutory retirement
(4-6). In the Netherlands, $7.3 \%$ of workers aged $65-70$ years and $3.3 \%$ of workers aged $71-75$ years prolonged their working career in 2003, but in 2014 this increased to $14.7 \%$ and $5.7 \%$, respectively (7). Working beyond retirement may provide a gradual transition from fulltime working to full-time retirement, but it might also create necessary additional income $(5,8)$. It is expected that an increasing number of retirees will work beyond retirement as the income resulting from old age pension becomes more insecure (8). In addition, many older

1 Department of Public and Occupational Health, Amsterdam Public Health Research Institute, VU University Medical Center Amsterdam, Amsterdam, The Netherlands.

2 Body@Work, Research Center on Physical Activity, Work and Health, Amsterdam, The Netherlands.

3 Department of Epidemiology \& Biostatistics, EMGO+ Institute for Health and Care Research, VU University Medical Center Amsterdam, Amsterdam,The Netherlands.

4 Department of Sociology, VU University Amsterdam, Amsterdam, The Netherlands.

5 Department of Economics and Development Economics, VU University Amsterdam, Amsterdam, The Netherlands.

6 Department of Work, Health \& Care, Netherlands Organisation for Applied Scientific Research TNO, Leiden, The Netherlands

Correspondence to: Cécile RL Boot, VU University Medical Center, Department of Public and Occupational Health, Van der Boechorststraat 7, 1081 BT Amsterdam, the Netherlands. [E-mail:crl.boot@vumc.nl] 
people desire to remain active after retirement (9).

It has been shown that retirement decisions are affected by forward-looking pension incentives (10), such as the "option value": the smaller the expected loss of income from retiring now rather than later, the higher the likelihood that people retire. The option value compares the retirement income in the current period to the retirement income at all possible points in the future (11). This might explain why people keep working after early retirement. On the other hand, social security policies that increase the incentives to work at older ages can reduce the labor force exit rate of older workers $(12,13)$. Being healthy was also associated with working beyond retirement (2). A study on work characteristics showed that high work engagement and high work time control were predictors of working beyond retirement $(2,14)$. Working in a smaller company, in the agricultural or service sector also predicted working beyond retirement (15). Furthermore, the social environment, such as the societal norm that older adults should be able to work past retirement has been found to be associated with working beyond retirement (16).

When health is the main subject of interest, studies often take only a few variables on the socioeconomic situation into account, eg, household income in a few categories, opinions on financial situation, or the possibility to stop working before the age of 65 . As occupational health studies usually rely on questionnaire data, the socioeconomic variables are often self-reported. The perception of one's financial situation is conceptually different from income and other financial variables based on administrative data. It has been shown that if retirees have a poor financial situation, they more often decide to work beyond retirement $(4,8,14)$. However, another study found no evidence that financial factors predict working beyond retirement (17).

Studies that took into account general health factors in addition to socioeconomic data showed inconclusive results for work participation. One study showed that individuals in good health had the largest probability of exit from employment before reaching the retirement age when controlled for financial incentives (9), while another study showed that individuals with different levels of health did not respond differently to financial incentives (11). If these findings are translated to working beyond retirement, this might mean that especially people in less-than-good health might work beyond retirement. If the main focus of the study is on socioeconomic variables and health information is available, this information generally consists of few general health measures included in, for example, household panel surveys. More detailed information about health and limitations is not included in these type of broad panel surveys or administrative registers. Therefore, to obtain a more comprehensive view on the role of health and the socioeconomic situation, it is crucial to take into account detailed information about health as well as income and other financial variables.

No study so far has combined detailed register-based socioeconomic information with data on health, demographics, work characteristics and the social environment. Combining these factors in one study could give insight into the contribution of each group of characteristics to the prediction of working beyond retirement. Therefore, the aim of this study is to explore whether socioeconomic, health, demographic, work characteristics, and social environmental characteristics independently predict working beyond retirement.

\section{Methods}

\section{Datasets}

This study made use of data of the Study on Transitions in Employment, Ability and Motivation (STREAM), a Dutch longitudinal study of 15118 people aged 45-64 years, including employees ( $\mathrm{N}=12$ 055), self-employed persons $(\mathrm{N}=1029)$, and persons without paid employment $(\mathrm{N}=2034)$ (18). Respondents participated in an online panel and completed an online questionnaire in 2010, 2011, 2012, and 2013. The study population of STREAM has been extensively described elsewhere (18). The blocks retrieved from STREAM were health, demographic, work characteristics, and social environmental characteristics.

Questionnaire data of STREAM was linked to register data of Statistics Netherlands containing socioeconomic data at individual level. The socioeconomic variables retrieved from the registers were income, equity, and pension entitlements. The following registers were used: integral personal income, capital equity of households in the Netherlands, and pension entitlements (19).

\section{Inclusion and exclusion criteria}

Figure 1 shows the flowchart of the study sample. Inclusion criteria were being an employee at baseline and aged 56-64 years. Some respondents $(\mathrm{N}=274)$ who had given permission for linking could not be linked because they did not exist in the municipal registration (GBA) or did not have a social security number. Only respondents $\geq 56$ years were included because the proportion of employees that had retired after one, two or three years of follow-up strongly increased from this age onwards (14). Respondents with missing values were removed from analyses. In total, $\mathrm{N}=1070$ respondents were included. For the purpose of internal validation, the total study population was randomly divided into $66 \%(\mathrm{~N}=700)$ and $34 \%(\mathrm{~N}=370)$. 


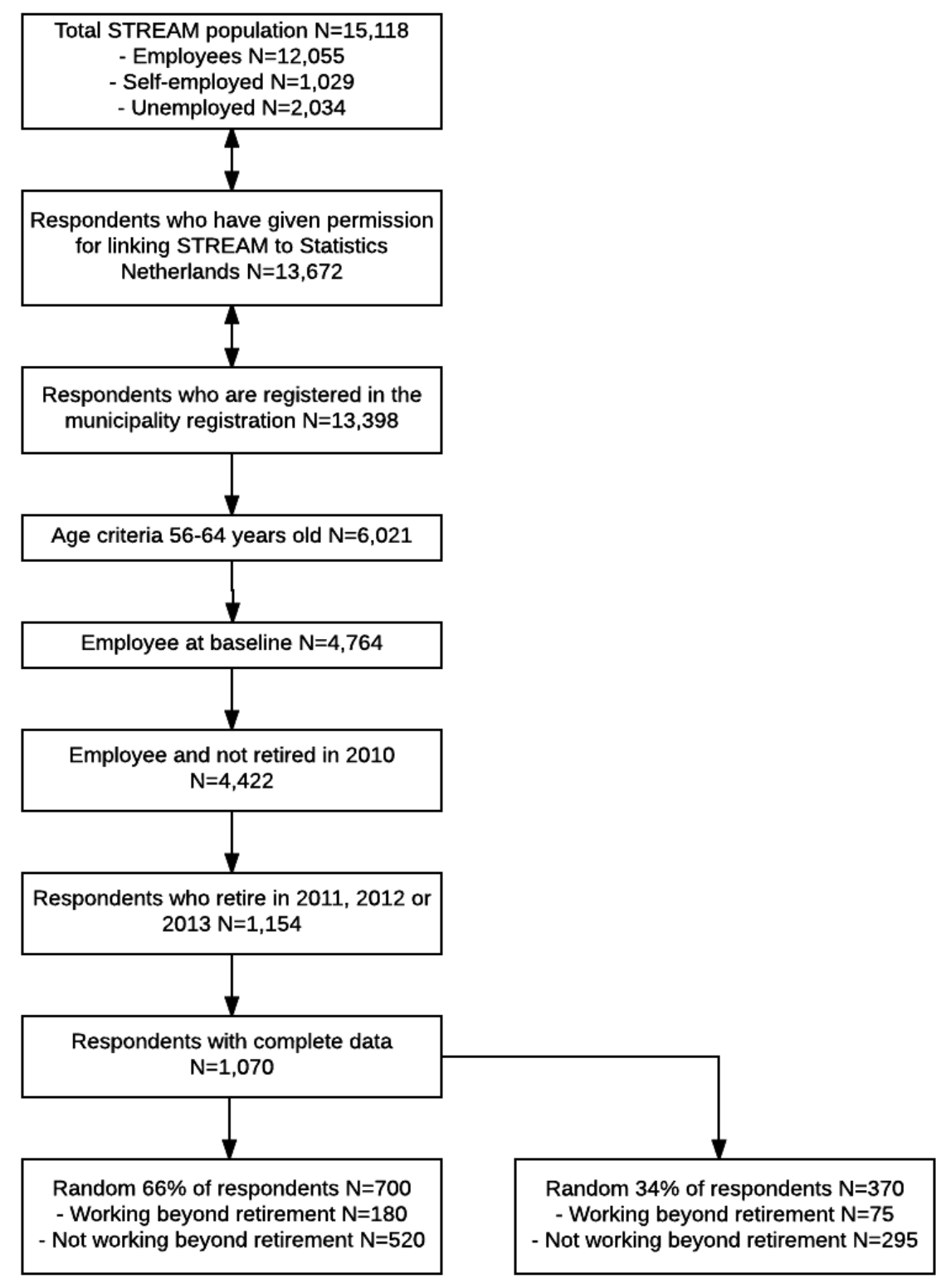

Figure 1. Flowchart of participants

\section{Dependent variable}

The dependent variable, ie, working beyond retirement, was based on self-reported data (STREAM). The respondents answered a question in which they indicated their employment status according to the following answering options: having a paid job, having more than one paid job, self-employed, unemployed, work disabled, early retirement, retirement, studying or homemaker. Working beyond retirement was defined as working beyond either early or statutory retirement in 2011, 2012 or 2013. This means that respondents who filled in that they were employed and (early) retired were considered as working beyond retirement. The reference group consisted of respondents who were on early or statutory retirement and not working in any of the consecutive years. The exact time between (early) retirement and starting to work following retirement is not known, but only in periods of one year.

\section{Potential predictors}

All potential predictors were categorized into one of five blocks: socioeconomic, health, demographic, work characteristics, and the social environment. These blocks were derived from the research framework of STREAM (18). According to this framework, variables in the blocks health, work (job characteristics, skills and knowledge), social, and financial factors influence work productivity and transitions in employment status 
through ability, motivation and opportunity to work (18). However, the main interest of this framework is not on working beyond retirement but rather paid work and the transition to (early) retirement (20). As currently there is no model available for working beyond retirement, we decided to use the blocks of this research framework as a guide to select potential predictors for the present study. In line with the guidelines for prognostic prediction models, we selected all variables that we hypothesized could be associated with working beyond retirement (21). The large number of potential predictors is in line with the explorative character of the present study resulting from the relatively small current knowledge base on working beyond retirement.

All potential predictors were retrieved from the STREAM cohort, except for the register-based socioeconomic variables, which came from the Statistics Netherlands' registers. All potential predictors were based on baseline information (2010). Predictors were dichotomized based on content (eg, permanent contract (yes/no) was based on permanent contract, temporary contract, out-sourced labor, or worker in social workplace) or on frequency distribution (eg, years of physically heavy work was dichotomized on the median).

Socioeconomic characteristics. All factors in this block were derived from register data from Statistics Netherlands: personal income, option value, possessions of household, financial possessions of household, savings, value house, mortgage, other debts, breadwinner (yes/no), owning a house (yes/no), income and equity quartiles.

Net personal income, possessions of household, financial possessions of household, savings, value of house, mortgage and other debts were all expressed in euros. Due to skewed distributions, all inputs were log transformed. The option value compares the income due to retirement in the current period to the income of retiring at all possible points in the future (11). In this study, the option value was operationalized using two variables: the maximum amount of old age benefit a respondent could have accrued in 2010 subtracted by the total amount of old age benefit a respondent receives if he or she retires now, after which a log transformation was performed. In this study, retirement income included the state pension and the employer-based pension. Retirement income due to pension insurances were not available from the registers. However, pension insurance is only available for a very small group of workers. Income and equity of respondents were categorized into quartiles. Equity is defined as the difference in monetary value between possessions and debts.

Health. The SF-12 measures health and functional wellbeing and is divided into two subscales: the physical component summary and the mental component sum- mary (22). Each scale consists of six questions. Scores were calibrated so that 50 was the average score (23). Depression, measured with a shortened 10 -item version of the Center for Epidemiologic Studies Depression Scale (CES-D), is about depressive symptoms in the past week $(24,25)$. The final score consisted of the mean score on all ten items. Higher mean scores indicate more depressive symptoms. Body weight, body height and body mass index (BMI) were also included. Mastery was measured using the 7-item Pearlin Mastery Scale (26). Recovery and relaxation was measured by three questions from the questionnaire on Demand-Induced Strain Compensation Recovery (DISC-R) about whether a person can relax and recover from his or her working day. In this study, final scores consisted of the mean score on all items. Higher mean scores indicate better mastery and recovery.

Self-perceived health, part of the SF-12, was assessed using the question: "how is your health in general?" The response categories were dichotomized into "excellent and (very) good" and "moderate and poor" health. Three items originating from the SF-36 were included: full of life, fatigue, and worn out in the past four weeks. The items were converted into a dichotomous variable (yes/ no). We added the three questions from the SF-36 as these reflect a general perception of health, rather than specific physical or mental aspects.

The presence of a chronic disease (complaints of hands or arms, legs or feet, back or neck, severe headaches, cardiovascular disease, lung disease, gastrointestinal disorders, diabetes, severe skin disease, psychological complaints, hearing problems, epilepsy, life-threatening disease, problems with vision or other longstanding diseases) was dichotomized into a single question (yes/no), as well as the presence of limitations at work resulting from chronic health conditions (yes/ no). Workers without a chronic disease were assumed to have no limitations at work resulting from chronic health conditions. Four questions on back, neck and shoulders, arms and hands, or legs and feet symptoms in the past 12 months were included. These questions were converted into a dichotomous variable (yes/no). Active lifestyle was measured using two questions. The first question addressed how many days per week someone was physically active for $\geq 30$ minutes. The other question focused on the number of days intensively physically active for $\geq 20$ minutes. Both questions were dichotomized by the median ( $<2$ days $/ \geq 2$ days). Smoking was dichotomized (yes/no). Finally, the experience of a life event (got a serious illness, death of partner, death of friend or family member, partner got serious disease, family member or friend got serious disease, divorce, other family problems, large financial problem, robbery, moved house or other major event) was dichotomized (yes/no). In line with research framework of STREAM, mastery and life events were classified into the health block. 
Demographic characteristics. Demographic variables included in the analyses were age (years) gender (female), household composition (living with or without partner), and level of education (low, intermediate, high).

Work characteristics. Number of working hours and days per week were included as continuous factors. A mean score on physical load was calculated from the following five items: force, using tools machines or vehicles, work in uncomfortable postures, standing for long periods of time, and kneeling or squatting for long periods of time. Job demands (four items) and autonomy (five items) were measured using the Job Content Questionnaire (27). Mental load was measured using three items: "need to think hard", "keep mind on the job", and "require much attention to the job" (28). Emotional load, taken from the Copenhagen Psychosocial Questionnaire, was measured as the mean score of four items (29). Social support from colleagues, also taken from the Copenhagen Psychosocial Questionnaire, was measured as the mean score of four items (29). In this study, higher scores indicated higher physical load, job demands, autonomy, mental load, emotional load, and social support. Procedural justice was measured using 3 items related to taking into account the opinion of employees about equal treatment of employees and about whether complaints of the employees are taken seriously. Distributive justice was measured by calculating mean scores of three questions about salary and three about appreciation from colleagues (30). Age discrimination was measured by asking the opinion of workers on how the company they work for is treating older workers. In this study, higher scores indicated more procedural justice, distributive justice, and age discrimination. Years of paid work was also taken into account.

The following dichotomized work characteristics were taken into analyses: profession (handcraft, transport, administrative, commercial, services, healthcare, education, specialist, supervision or other combined with agriculture), company size (small ( $<10$ employees), intermediate (10-99 employees), or large ( $\geq 100$ employees); having a permanent contract (yes/no); supervisory tasks (yes/no); restructuring (yes/no); screen work $(<4$ $1 \geq 4$ hours); noise (yes/no); working with substances (yes/no); evening or night shifts (yes/no) and intimidation (yes/no) referred to intimidation by supervisors, colleagues or customers in the past 12 months. Finally, years of physically heavy work ( $<8 / \geq 8$ years), years of emotionally heavy work $(<8 / \geq 8$ years), and years of mentally heavy work $(<16.5 / \geq 16.5$ years $)$ were taken into account.
Social environmental characteristics. The work status of the partner was investigated by asking if the partner is currently in one of the following situations: salaried employment, self-employed, unemployed, work disabled, homemaker, retired, studying, volunteer work or informal care. The response categories were yes and no. If the respondent did not have a partner, the answer to all questions was no. The question "what would your partner think if you stopped working before the official retirement age" was transformed into three answer categories [(very) unpleasant, neither pleasant nor unpleasant/pleasant, no partner]. The question "what would your partner think if you continued working until the official retirement age" was transformed into six response categories (very unpleasant, unpleasant, neither pleasant nor unpleasant, pleasant, very pleasant, no partner). Two items about missing or neglecting family activities due to work or work activities due to family were included. The questions were dichotomized (yes/no).

\section{Statistical analysis}

Univariate associations between all independent variables and the dependent variable working beyond retirement were assessed by logistic regressions.

Per block, the correlations between the variables were assessed. If the Pearson correlation coefficient was $\geq 0.7$, the strongest predictor of working beyond retirement was chosen. Variables from the univariate analysis with $\mathrm{P}<0.15$ and correlations $<0.7$ with other independent variables were included in the block analyses. For the block analyses, we performed a logistic regression with backward selection separately for each block (socioeconomic, health, demographic, work characteristics and social environment). Per block, the area under the curve (AUC) represents the accuracy of the model. The accuracy depends on the extent to which the prediction model correctly separates the group into people who work beyond retirement and people who do not work beyond retirement. The variables from each block with $\mathrm{P}<0.15$ were included in a logistic regression backward selection to create one final model $(\mathrm{P}<0.05)$. We internally validated the final prediction model by building the prediction model on $67 \%$ of the population, and then applying the final model to the remaining 33\% of the population (31). The AUC of the internal validation model showed how well the model performed in a population that was not used to build the model on, while the Hosmer and Lemeshow test showed the model fit. Finally, post-hoc analyses are performed to show the differences between working after early retirement or statutory retirement. 
Table 1. Descriptive statistics representing means, standard deviations (SD), percentages (\%) and non-adjusted odds ratios (OR) with $85 \%$ confidence intervals $(85 \% \mathrm{Cl})$ of all potential predictors Potential predictors with a $\mathrm{P}$-value $<0.150$ are shown in bold.

\begin{tabular}{|c|c|c|c|c|c|}
\hline & \multicolumn{5}{|c|}{ Total population $\mathrm{N}=761$} \\
\hline & Mean & SD & $\%$ & $\mathrm{OR}$ & $85 \% \mathrm{Cl}$ \\
\hline \multicolumn{6}{|l|}{ Socioeconomic } \\
\hline Income a & 37.7 & 7.9 & & 1.085 & $0.946-1.244$ \\
\hline Option value a & 6.6 & 3.0 & & 0.955 & $0.920-0.991$ \\
\hline Possessions a & 11.2 & 3.6 & & 0.973 & $0.937-1.010$ \\
\hline Financial possessions $^{\text {a }}$ & 9.5 & 3.3 & & 0.973 & $0.933-1.014$ \\
\hline Savings a & 9.2 & 3.5 & & 0.974 & $0.937-1.013$ \\
\hline Value house a & 6.9 & 8.8 & & 0.992 & $0.976-1.009$ \\
\hline Mortgage a & 5.0 & 8.9 & & 0.993 & $0.977-1.009$ \\
\hline Other debts a & -5.0 & 5.2 & & 1.005 & $0.978-1.033$ \\
\hline Breadwinner (yes) & & & 24.6 & 0.811 & $0.610-1.077$ \\
\hline Own house (yes) & & & 48.8 & 30.871 & $0.686-1.106$ \\
\hline \multicolumn{6}{|l|}{ Quartile income (\%) } \\
\hline $0-25$ & & & 11.7 & 71.000 & Reference \\
\hline $26-50$ & & & 14.6 & 1.109 & 0.68 \\
\hline $51-75$ & & & 37.8 & 0.946 & $0.622-1.440$ \\
\hline $76-100$ & & & 35.9 & 1.641 & $1.089-2.474$ \\
\hline \multicolumn{6}{|l|}{ Quartile equity (\%) } \\
\hline $0-25$ & & & 38.6 & 1.000 & Reference \\
\hline $26-50$ & & & 14.2 & 0.942 & $0.660-1.347$ \\
\hline $51-$ & & & 22.5 & 50.539 & $0.385-0.755$ \\
\hline $76-10$ & & & 24.7 & 0.758 & $0.559-1.029$ \\
\hline \multicolumn{6}{|l|}{ Health } \\
\hline SF12 - physical (average 50) & 50.7 & 8.2 & & 1.043 & $1.025-1.062$ \\
\hline$S F 12-n$ & 54.0 & 7.1 & & 1.007 & $90-1.025$ \\
\hline ore 1-4) & 1.5 & 0.4 & & 0.619 & $0.453-0.847$ \\
\hline Body $\mathrm{h}$ & 174.6 & 9.2 & & 1.033 & 9-1.047 \\
\hline Body & 82.8 & 15.4 & & 1.001 & 1.008 \\
\hline BMI ( & 27.1 & 4.4 & & 0.957 & 0.9 \\
\hline core 1-5) & 3.8 & 0.6 & & 0.992 & $0.814-1.207$ \\
\hline Recovery/relaxation (score 1-5) & 3.0 & 0.8 & & 0.827 & $0.706-0.969$ \\
\hline Chronic disease (yes) & & & 64.7 & 0.801 & $0.625-1.028$ \\
\hline th (very good & & & 84.0 & 1.714 & $1.193-2.463$ \\
\hline Feels $\mathrm{f}$ & & & 84.6 & 1.836 & 2.673 \\
\hline Feels & & & 91.0 & 1.898 & 3.098 \\
\hline Fatig & & & 84.1 & 1.772 & $5-2.562$ \\
\hline Limita & & & 67.6 & 6 1.4 & 1.1 \\
\hline Back complaints (no) & & & 39.4 & 41.196 & $0.935-1.530$ \\
\hline Neck complaints(no) & & & 49.4 & 41.097 & $0.859-1.402$ \\
\hline Arms complaints (no) & & & 63.8 & B 1.038 & $0.808-1.334$ \\
\hline Leg/feet complaints (no) & & & 55.2 & 21.415 & $1.106-1.810$ \\
\hline $\begin{array}{l}\text { Number days active for } \geq 30 \\
\text { minutes/week ( } \geq 2 \text { days) }\end{array}$ & & & 75.5 & 1.374 & $1.028-1.837$ \\
\hline $\begin{array}{l}\text { Number days intensively active } f \\
\geq 20 \text { minutes/week ( } \geq 2 \text { days) }\end{array}$ & & & 39.2 & 21.539 & $1.042-2.275$ \\
\hline Smoking (no) & & & 82.5 & 1.125 & -1.549 \\
\hline Life event (yes) & & & 47.8 & 30.866 & $0.682-1.100$ \\
\hline \multicolumn{6}{|l|}{ Demographic characteristics } \\
\hline Age (years) & 61.3 & 1.9 & & 1.065 & $9-1.134$ \\
\hline Gende & & & 39.4 & 40.591 & $0.458-0.762$ \\
\hline Partner (yes) & & & 76.2 & 1.160 & $0.872-1.544$ \\
\hline \multicolumn{6}{|l|}{ Education } \\
\hline Low & & & 28.3 & 31.000 & Reference \\
\hline Intermediate & & & 34.6 & 1.355 & $0.987-1.860$ \\
\hline High & & & 37.2 & 21.688 & $1.228-2.267$ \\
\hline \multicolumn{6}{|l|}{ Work characteristics } \\
\hline Working hours/week & 29.7 & 10.9 & & 0.992 & $82-1.003$ \\
\hline Working days/week & 4.1 & 1.1 & & 1.109 & $0.993-1.238$ \\
\hline Physical load (score 1-5) & 1.7 & 0.8 & & 0.850 & $0.732-0.987$ \\
\hline core 1-5) & 3.0 & 0.9 & & 0.939 & $0.810-1.088$ \\
\hline & 3.8 & 0.8 & & 1.028 & $0.880-1.202$ \\
\hline Ment & 4.2 & 0.7 & & 1.368 & $1.129-1.659$ \\
\hline Emoti & 2.5 & 0.8 & & 1.140 & $0.985-1.320$ \\
\hline Social support (score 1-5) & 3.5 & 0.8 & & 0.867 & $0.748-1.003$ \\
\hline
\end{tabular}

Table 1. Continued

Procedural justice (score 1-5) $3.3 \quad 0.8$

Distributive justice (score 1-3) $2.6 \quad 0.5$

Age discrimination (score 1-5) $2.6 \quad 0.9$

Years of paid work

$37.7 \quad 7.9$

Type of work/sector

Handcraft

Transport

Administrative work

Commercial work

Services

Healthcare

Education

Specialist

Supervisor

Other work

Company size

Small

Intermediate

Large

Permanent contract (yes)

Supervisory tasks (yes)

Reorganisation (yes)

Works behind screen ( $\geq 4$ hours)

Noise (yes)

Works with substances (yes)

Evening/night shifts (yes)

Intimidation (yes)

Physically heavy work ( $\geq 8$ years)

Emotionally heavy work ( $\geq 8$ years)

Mentally heavy work ( $\geq 8$ years)

Social environmental factors

Partner in paid employment (yes)

Partner is self-employed (yes)

Partner is unemployed ${ }^{b}$

Partner is work disabled

Partner is homemaker

Partner is retired

Partner is studying (yes) ${ }^{b}$

Volunteering partner (yes)

Opinion partner: stop working

No partner

(very) unpleasant

Neither pleasant/unpleasant/

pleasant

Opinion partner: continue

working

No partner

Very unpleasant

Unpleasant

Neither pleasant nor

unpleasant

Pleasant

Very pleasant

Missing family activities (yes)

Missing work activities (yes)

$1.228 \quad 1.058-1.426$

$1.192 \quad 0.930-1.529$

$0.931 \quad 0.807-1.073$

$1.009 \quad 0.993-1.025$

$\begin{array}{lll}7.1 & 0.213 & 0.100-0.454\end{array}$

$\begin{array}{llll}2.8 & 2.684 & 1.414-5.093\end{array}$

$\begin{array}{lll}16.4 & 0.796 & 0.569-1.112\end{array}$

$\begin{array}{lll}5.7 & 1.042 & 0.631-1.719\end{array}$

$\begin{array}{lll}8.7 & 0.907 & 0.589-1.397\end{array}$

$12.01 .657 \quad 1.178-2.331$

$\begin{array}{lll}13.3 & 0.989 & 0.696-1.406\end{array}$

$\begin{array}{lll}7.8 & 0.972 & 0.621-1.521\end{array}$

$\begin{array}{lll}8.8 & 1.241 & 0.828-1.859\end{array}$

$25.8 \quad 1.043 \quad 0.796-1.368$

$9.41 .000 \quad$ Reference

$\begin{array}{lll}20.4 & 0.802 & 0.522-1.231\end{array}$

$60.20 .699 \quad 0.467-1.047$

$\begin{array}{lll}92.0 & 0.431 & 0.291-0.639\end{array}$

$24.9 \begin{array}{lll}1.481 & 1.135-1.932\end{array}$

$37.3 \quad 0.930 \quad 0.726-1.192$

$\begin{array}{lll}46.9 & 0.962 & 0.758-1.222\end{array}$

$26.9 \quad 0.844 \quad 0.641-1.111$

$21.3 \quad 0.711 \quad 0.522-0.966$

$37.3 \quad 1.519 \quad 1.192-1.937$

$\begin{array}{lll}18.6 & 0.808 & 0.588-1.110\end{array}$

$\begin{array}{lll}49.2 & 0.726 & 0.558-0.945\end{array}$

$\begin{array}{lll}49.1 & 1.170 & 0.921-1.488\end{array}$

$50.01 .461 \quad 1.146-1.862$

$32.8 \quad 1.302 \quad 1.014-1.671$

$\begin{array}{lll}4.9 & 1.592 & 0.955-2.654\end{array}$

$\begin{array}{lll}2.4 & 0.815 & 0.357-1.861\end{array}$

$\begin{array}{llll}5.5 & 0.461 & 0.242-0.881\end{array}$

$\begin{array}{lll}16.4 & 1.155 & 0.842-1.584\end{array}$

$\begin{array}{lll}18.6 & 0.979 & 0.720-1.332\end{array}$

$\begin{array}{lll}0.5 & 0.954 & 0.180-5.051\end{array}$

$\begin{array}{lll}4.1 & 0.678 & 0.349-1.320\end{array}$

$24.31 .000 \quad$ Reference

$6.91 .906 \quad 1.171-3.101$

$68.81 .092 \quad 0.817-1.461$

a Log-transformed.

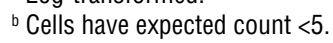

24.51 .000 Reference

$\begin{array}{lll}5.8 & 0.329 & 0.148-0.730\end{array}$

$\begin{array}{llll}13.0 & 0.458 & 0.275-0.764\end{array}$

$35.8 \quad 1.446 \quad 1.054-1.983$

$15.41 .872 \quad 1.285-2.726$

$\begin{array}{lll}5.4 & 0.932 & 0.511-1.698\end{array}$

$\begin{array}{lll}54.8 & 0.720 & 0.567-0.914\end{array}$

$\begin{array}{lll}71.7 & 0.811 & 0.625-1.051\end{array}$ 
Table 2. Results of the logistic regression backward selection of the blocks with $\mathrm{P}<0.15$ for working beyond retirement.

\begin{tabular}{|c|c|c|}
\hline & $\mathrm{OR}$ & $85 \% \mathrm{Cl}$ \\
\hline \multicolumn{3}{|l|}{ Socioeconomic } \\
\hline Option value & 0.925 & $0.886-0.965$ \\
\hline \multicolumn{3}{|l|}{ Quartile income $(\%)$} \\
\hline $0-25$ & 1.000 & reference \\
\hline $26-50$ & 1.330 & $0.785-2.253$ \\
\hline $51-75$ & 1.310 & $0.809-2.121$ \\
\hline $76-100$ & 2.525 & $1.547-4.120$ \\
\hline \multicolumn{3}{|l|}{ Quartile equity (\%) } \\
\hline $0-25$ & 1.000 & reference \\
\hline $26-50$ & 0.898 & $0.617-1.307$ \\
\hline $51-75$ & 0.504 & $0.357-0.712$ \\
\hline $76-100$ & 0.742 & $0.542-1.016$ \\
\hline \multicolumn{3}{|l|}{ Health } \\
\hline SF-12 (physical component scale) & 1.040 & $1.021-1.059$ \\
\hline Depression & 0.712 & $0.506-1.000$ \\
\hline$\geq 2$ days intensively physically active & 1.447 & $1.121-1.867$ \\
\hline Body height & 1.031 & $1.017-1.045$ \\
\hline Recovery and relaxation & 0.786 & $0.647-0.912$ \\
\hline \multicolumn{3}{|l|}{ Demographic characteristics } \\
\hline \multicolumn{3}{|l|}{ Education } \\
\hline Low & 1.000 & reference \\
\hline Intermediate & 1.355 & $0.987-1.860$ \\
\hline High & 1.668 & $1.228-2.267$ \\
\hline \multicolumn{3}{|l|}{ Work characteristics } \\
\hline Works in handcraft & 0.303 & $0.139-0.659$ \\
\hline Works in transport & 3.201 & $1.587-6.456$ \\
\hline Works in healthcare & 1.634 & $1.141-2.340$ \\
\hline Permanent contract & 0.425 & $0.281-0.643$ \\
\hline Gives supervision & 1.451 & $1.095-1.923$ \\
\hline Works evening/night shifts & 1.324 & $1.025-1.711$ \\
\hline$\geq 8$ years in physically heavy work & 0.736 & $0.553-0.979$ \\
\hline$\geq 16.5$ years in mentally heavy work & 1.351 & $1.049-1.739$ \\
\hline \multicolumn{3}{|l|}{ Social environment } \\
\hline Partner is work disabled & 0.490 & $0.251-0.955$ \\
\hline \multicolumn{3}{|l|}{$\begin{array}{l}\text { Opinion partner on continue working until } \\
\text { retirement age }\end{array}$} \\
\hline Very unpleasant & 0.369 & $0.165-0.824$ \\
\hline Unpleasant & 0.472 & $0.283-0.789$ \\
\hline Neither pleasant, nor unpleasant & 1.530 & $1.112-2.104$ \\
\hline Pleasant & 1.933 & $1.321-2.830$ \\
\hline Very pleasant & 0.925 & $0.505-1.694$ \\
\hline No partner & 1.000 & \\
\hline Missing or neglecting family activities & 0.676 & $0.527-0.868$ \\
\hline
\end{tabular}

\section{Results}

\section{Population description}

Table 1 describes the population characteristics. One fourth of the sample worked beyond retirement $(\mathrm{N}=197)$. The mean age of people who worked beyond retirement was 61.3 years and the majority was male. Approximately $65 \%$ of the population had a chronic disease, while on average $84 \%$ of the population assessed their health as good. On average, people participated in paid work for 37.7 years. Their working hours per week were approximately 30 hours. Seventy-two percent missed work activities due to family, $55 \%$ missed family activities due to work (55\%).
Table 1 shows all variables that were included in the univariate analyses. The correlations between variables within the socioeconomic block ranged from $0.02-0.44$, while the correlations between variables within the health block ranged from $-0.57-0.62$. The correlations between variables within the block work characteristics ranged from $-0.27-0.39$, while the correlations between variables within the block social environmental characteristics ranged from $-0.41-0.68$. Only one combination of variables from different blocks had a high correlation; gender and body height had a correlation coefficient of -0.70 , based on which only the strongest predictor (ie, body height) was taken into account.

Table 2 presents the results of the multivariate analyses per block. The amount of variables with significance $\mathrm{P}<0.15$ included in each block ranged from one (demographics) to eight (work characteristics). In total 20 variables were left from the five block models as input for the final model, combining the results from all block analyses into one model.

The final model consisted of seven variables (table 3). Looking at the results of the final model, from the block health characteristics, only a higher score on the physical component scale of the SF-12, being intensively physically active for $\geq 20$ minutes for $\geq 2$ days/week, and taller body height remained in the final model and increased the likelihood to work longer beyond retirement. Within the block work characteristics, respondents with a permanent contract and who worked in handcraft were less likely to work beyond retirement, but respondents who worked in healthcare were more likely to work beyond retirement. Of the social environmental characteristics, only a negative opinion of the partner about working until retirement was associated with not working beyond retirement. None of the socioeconomic and demographic characteristics remained in the final model. Furthermore, the effect sizes of the post-hoc models pointed in the same direction.

From table 4 it can be seen that the AUC of the final model was $73 \%(\mathrm{P}<0.05)$. The Hosmer and Lemeshow test showed that the model had a good fit, because the test was not significant. The receiver operating characteristic (ROC) curve of the internal validation decreased to $68 \%$, indicating slight overestimation of the coefficients of the first sample. Here too, the Hosmer and Lemeshow test was not statistically significant, indicating that there was a good model fit. The AUC of all blocks ranged from $55-65 \%$.

If the final model is applied to the validation sample (post-hoc analysis), it can be seen in table 4 that the model on early retirement and continued working has a higher AUC (75\%) than the model for statutory retirement $(69 \%)$. 
Table 3. Logistic regression backward selection for working beyond retirement, $\mathrm{P}$-value $<0.05$ [OR=0dds ratio; $95 \%$ Cl=95\% confidence interval.]

\begin{tabular}{|c|c|c|c|c|c|c|c|c|}
\hline \multirow[t]{2}{*}{ Variables } & \multicolumn{2}{|c|}{ Final model } & \multicolumn{2}{|c|}{ Internal validation } & \multicolumn{2}{|c|}{$\begin{array}{l}\text { Post-hoc model for } \\
\text { early retirement }\end{array}$} & \multicolumn{2}{|c|}{$\begin{array}{l}\text { Post-hoc model for } \\
\text { statutory retirement }\end{array}$} \\
\hline & OR & $95 \% \mathrm{Cl}$ & $\mathrm{OR}$ & $95 \% \mathrm{Cl}$ & $\mathrm{OR}$ & $95 \% \mathrm{Cl}$ & $\mathrm{OR}$ & $95 \% \mathrm{Cl}$ \\
\hline SF-12 (physical component scale) & 1.047 & $1.020-1.075$ & 1.037 & $1.001-1.074$ & 1.035 & $0.999-1.073$ & 1.047 & $1.014-1.082$ \\
\hline$\geq 2$ days intensively physically active & 1.571 & $1.084-2.276$ & 1.384 & $0.809-2.367$ & 1.293 & $0.778-2.150$ & 1.601 & $1.001-2.562$ \\
\hline Body height & 1.046 & $1.025-1.068$ & 1.011 & $0.981-1.041$ & 1.051 & $1.022-1.082$ & 1.030 & $1.004-1.058$ \\
\hline Works in handcraft & 0.167 & $0.049-0.571$ & 0.522 & $0.114-2.391$ & 0.183 & $0.040-0.829$ & 0.115 & $0.015-0.902$ \\
\hline Works in healthcare & 1.902 & $1.118-3.234$ & 1.331 & $0.634-2.794$ & 2.201 & $1.106-4.381$ & 1.841 & $0.890-3.807$ \\
\hline Permanent contract & 0.405 & $0.214-0.769$ & 0.429 & $0.191-0.967$ & 0.385 & $0.147-1.007$ & 0.428 & $0.209-0.878$ \\
\hline \multicolumn{9}{|l|}{$\begin{array}{l}\text { Opinion partner on continue work- } \\
\text { ing until retirement age }\end{array}$} \\
\hline Very unpleasant & 0.198 & $0.055-0.716$ & 0.139 & $0.017-1.111$ & 0.234 & $0.049-1.127$ & 0.143 & $0.017-1.228$ \\
\hline Unpleasant & 0.354 & $0.172-0.770$ & 0.528 & $0.189-1.478$ & 0.346 & $0.131-0.916$ & 0.512 & $0.174-1.502$ \\
\hline Neither pleasant, nor unpleasant & 1.138 & $0.710-1.824$ & 1.202 & $0.615-2.351$ & 1.446 & $0.743-2.814$ & 1.044 & $0.572-1.906$ \\
\hline Pleasant & 1.605 & $0.913-2.822$ & 1.504 & $0.647-3.494$ & 2.091 & $0.912-4.791$ & 1.473 & $0.747-2.905$ \\
\hline Very pleasant & 0.549 & $0.218-1.382$ & 0.597 & $0.154-2.316$ & 0.569 & $0.112-2.890$ & 0.610 & $0.230-1.619$ \\
\hline No partner & 1.000 & reference & 1.000 & Reference & 1.000 & Reference & 1.000 & reference \\
\hline
\end{tabular}

Table 4. Characteristics of the different models. [AUC=area under the curve; $95 \% \mathrm{Cl}=95 \%$ confidence interval.]

\begin{tabular}{|c|c|c|c|c|c|c|}
\hline Model & $\mathrm{N}$ & $\begin{array}{c}\mathrm{N} \text { (working } \\
\text { beyond retirement) }\end{array}$ & $\begin{array}{c}\text { Hosmer and } \\
\text { Lemeshow }\end{array}$ & $\mathrm{R}^{2}$ & AUC & $95 \% \mathrm{Cl}$ \\
\hline Socioeconomic block & 728 & 191 & 0.354 & 5.1 & 0.630 & $0.584-0.676$ \\
\hline Health block & 725 & 187 & 0.649 & 7.2 & 0.639 & $0.595-0.684$ \\
\hline Demographics block & 761 & 197 & 1.000 & 1.1 & 0.554 & $0.508-0.600$ \\
\hline Work characteristics block & 737 & 190 & 0.465 & 8.3 & 0.648 & $0.603-0.693$ \\
\hline Social environmental block & 736 & 192 & 0.832 & 7.1 & 0.634 & $0.590-0.677$ \\
\hline Final model & 700 & 180 & 0.081 & 18.3 & 0.727 & $0.686-0.768$ \\
\hline Internal validation & 370 & 75 & 0.882 & 11.4 & 0.678 & $0.612-0.745$ \\
\hline Post-hoc model for early retirement & 425 & 97 & 0.350 & 20.4 & 0.752 & $0.700-0.804$ \\
\hline Post-hoc model for statutory retirement & 399 & 111 & 0.621 & 15.6 & 0.693 & $0.638-0.748$ \\
\hline
\end{tabular}

\section{Discussion}

This study showed that health, work, and social environmental characteristics predicted working beyond retirement. However, register-based socioeconomic and demographic characteristics did not independently contribute to the prediction of post retirement work.

Previous research showed that socioeconomic characteristics, such as a poor financial situation, was a good predictor of working beyond retirement (14). In this study, the analyses for the socioeconomic block showed that an increase in the option value decreased the chances of working beyond retirement. Research focusing on retirement showed that people with a high option value are more likely to work until the official retirement age $(9,11)$. However, working beyond retirement does not relate to changes in retirement benefits as the maximum amount of old age benefit is related to the statutory retirement age. This might explain the contrasting findings in our study compared to the studies focusing on retirement. In addition, we showed that the association between register-based socioeconomic factors and working beyond retirement disappeared when other factors were added to the model. This sug- gests that register-based socioeconomic characteristics do not contribute to the prediction of working beyond retirement independently in addition to the other factors in the model. Another explanation for this may be that current health and work characteristics are more important for the decision not to retire than the current socioeconomic status. Another explanation may be that the actual value of income or equity does not matter, but that it matters more how a respondent thinks about his or her financial situation (14). We have performed an additional analysis including a self-reported socioeconomic predictor (results not shown). This analysis showed that people who consider themselves to be short on money are more likely to continue working after retirement. The entrance of this variable into the model resulted in the exclusion of physical activity from the final model. This can be explained by the fact that people with a higher socioeconomic status are more active.

People with less-than-good perceived health are less likely to continue working beyond retirement (32, 33). In this study, healthier people were more likely to work beyond retirement. When planning retirement individuals may take into account that their health might deteriorate in the future (32). Our finding that taller respondents are more likely to work beyond retirement 
might partly be explained by health as well. In previous studies, low body height was associated with adverse childhood living conditions, long standing illness, and poor or moderate perceived health (34).

Previous studies showed that men and workers with higher levels of education were more likely to work beyond retirement (15). However, in this study education was not predictive for working beyond retirement. It is likely that at the end of working careers, education is of less importance than the other characteristics. In this study, working in healthcare was positively associated with working beyond retirement, compared to working in any other sector. In the Netherlands, the decision to remain in the workforce at older ages for nurses is based on the possibility to change the content of the work, attention to working conditions, possibilities to change working hours, attention to the career path of the older nurse and attention to health (35). If these conditions are met, this may facilitate working beyond retirement of nurses. In addition, as there is a shortage of personnel in healthcare (36), the availability of work for experienced nurses is large. Moreover, it might be relatively easy for nurses to start working at another organization for a few hours. If a respondent works in handcraft, it is less likely that the respondent will continue working after retirement. This contrasting effect between healthcare and handcraft might be explained by different collective labor agreements between sectors. In some sectors, workers have more opportunities to choose for early retirement at a younger age. This implies that they will also have to decide about working beyond retirement at a younger age.

Given the decrease in the ROC curves from $73-68 \%$, model fit was good, even though the internal validation showed that the regression coefficients of the final model were slightly overestimated. As we used backward regression analyses, we performed sensitivity analyses to test if the sequence of entering variables (health, socioeconomic versus socioeconomic, health) into the regression equation influenced the results, which was not the case. Furthermore, we performed post-hoc analyses to test the difference between statutory and early retirement. From these results it can be seen that the AUC is higher for early retirement and continue working beyond retirement. This means that the model separates people who retire early and work beyond retirement and people who retire early and do not work beyond retirement better than for statutory retirement. Unfortunately, it was not possible to differentiate the groups from the beginning due to power issues. The time between (early) retirement and starting to work following retirement is only known in periods of one year. However, it is likely that people made arrangements for continuing work before retirement, therewith allowing a continuity of work.

The strength of this study is that it is the first study to combine self-reported and register-based variables into one model to predict working beyond retirement. By combining these different data sources, an interdisciplinary approach emerges as economists most often use register-based variables, and (occupational) epidemiologists frequently rely on self-reported data. Combining data and views from different disciplines is crucial to increase our understanding of working beyond retirement, as both disciplines have knowledge about different predictors that likely interact. This paper shows that detailed health information might be stronger associated with working beyond retirement than register-based socioeconomic factors. When detailed health information is not taken into account in register-based studies, important information about determinants of working beyond retirement might be missed. In addition, we had access to a large dataset, which enabled us to build our prediction model on $2 / 3^{\text {rd }}$ of the population and internally validate it on the remaining $1 / 3^{\text {rd }}$.

Limitations of this study include our reliance on selfreports for the variables retrieved from the STREAM cohort, such as health status of the respondents. It might be the case that respondents assess their health differently even though it might be the same. However, a study has shown that self-perceived health was a good predictor of number of physician contacts per year and mortality (37), which might mean that self-reported variables are good predictors due to the fact that it expresses the opinion of the respondent. A limitation of the register-based socioeconomic data is that private pensions are not included in the registers. The amount of pension received and accrued might be underestimated. However, only a few people in the Netherlands have a private pension. A disadvantage of prediction models is that statistics play a large role in the selection of variables in the final model. Although a prediction model can be considered a first step towards a better insight into a relatively new topic of investigation, it implies that a large number of variables are likely to be included in the initial analyses. This study shows that, out of the initial set of variables, a combination of only seven variables best predicted working beyond retirement. Finally, the categorization of variables may be a topic of debate, eg, educational level might be considered a demographic variable as well as a socioeconomic variable. However, as our analyses ultimately led to one final model combining predictors from all categories, this will not have influenced the results.

Future research on work participation by older workers should attempt to incorporate both types of data, and therewith embrace a multidisciplinary approach to obtain a better understanding of this multifactorial issue. This is particularly relevant in the context of policy decisions as these are often supported by register-based analyses only. In addition, differences between working 
beyond early and statutory retirement deserve attention in future studies. It might be especially interesting to focus on early retirement at different ages as people aged 58-60 years might have different motives for retiring than people aged 61-64 years. Finally, the external validation of the prediction model is a topic for further research as this will gain insight into the model properties in another population.

This study can inform Dutch policymakers about which groups are more likely to prolong their working lives. In this study, the respondents are relatively healthy, because all included people worked until (early) retirement. Furthermore, the people who became unemployed or work disabled were not included in our sample. However, the increase of the official retirement age by the Dutch government and the abolishment of early retirement, as well as stricter rules for disability pension lead to an overall increase of the retirement age. This means that more people, even people with poor health, will be pushed towards working until the official retirement age. Although, the effect of the healthy worker effect might be decreasing, there still will be a healthy worker effect as people with poor health might exit from work earlier.

The present study provides indications that the group that prolonged work participation beyond retirement can be identified from the total population of older workers by health, work, and environmental characteristics. On the other hand, register-based socioeconomic characteristics and demographic characteristics were not found to predict working beyond retirement.

\section{Acknowledgments}

We thank Statistics Netherlands (CBS) for supplying us with the socioeconomic data. According to the Dutch Research involving Human Subjects Act (WMO), this study was not subject to an ethical review. The authors declare no conflicts of interest.

\section{References}

1. Janssen B, Souren M. Naar een arbeidsdeelname van 80 procent in 2016 [Towards work participation of 80 percent in 2016]. Den Haag: 2009. Report No.: Contract No.: 2.

2. Virtanen M, Oksanen T, Batty GD, Ala-Mursula L, Salo $\mathrm{P}$, Elovainio M, et al. Extending employment beyond the pensionable age: a cohort study of the influence of chronic diseases, health risk factors, and working conditions. PloS one. 2014;9(2):e88695. https://doi.org/10.1371/journal. pone. 0088695

3. Centraal Bureau voor de Statistiek. Meer dan de helft van de werknemers bij pensionering 65 jaar of ouder [More than half of the employees is aged 65 years or older]. Den Haag: Centraal Bureau voor de Statistiek; 2015 [updated 2/5/2015; cited 2015 6/20/2015]. Available from: https://www.cbs.nl/nlnl/nieuws/2015/06/meer-dan-de-helft-van-de-werknemersbij-pensionering-65-jaar-of-ouder.

4. Dingemans E, Henkens KA. Involuntary retirement, bridge employment, and satisfaction with life: A longitudinal investigation. J Org Behav. 2014;35(4):575-91. https://doi. org/10.1002/job.1914

5. Adams G, Rau B. Job seeking among retirees seeking bridge employment. Personnel Psychology. 2004;57(3):719-44. https://doi.org/10.1111/j.1744-6570.2004.00005.x

6. Dingemans E. Werken en willen werken na pensioen [Work participation and wanting to work beyond retirement]. Geron. 2015;17(1):56-60.

7. Centraal Bureau voor de Statistiek. Arbeidsdeelname: kerncijfers [Work participation: key figures]. Den Haag: Centraal Bureau voor de Statistiek; 2016 [updated 8/12/2016; cited 2015 6/20/2015]. Available from: http://statline.cbs.nl/ StatWeb/publication/?VW $=\mathrm{T} \& \mathrm{DM}=\mathrm{SLNL} \& \mathrm{PA}=82309 \mathrm{NE}$ $\mathrm{D} \& \mathrm{LA}=\mathrm{NL}$.

8. Dingemans E, Henkens K, Van Solinge H. Doorstarten na pensioen: een opkomend fenomeen [New start after retirement: an upcoming phenomenon]. Demos. 2013;29(8):1-3.

9. Kalwij A, de Vos K, Kapteyn A. Health, Disability Insurance and Labor Force Exit of Older Workers in the Netherlands. Social Security Programs and Retirement Around the World: Disability Insurance Programs and Retirement: University of Chicago Press; 2014.

10. Chan S, Stevens AH. Do changes in pension incentives affect retirement? A longitudinal study of subjective retirement expectations. J Public Econ. 2004;88(7):1307-33. https://doi. org/10.1016/S0047-2727(02)00223-2

11. Banks J, Emmerson C, Tetlow GC. Effect of Pensions and Disability Benefits on Retirement in the UK. NBER Working paper 2014; No. 19907.

12. Coile C, Gruber J. Social security and retirement. NBER Working paper 2000;no. 7830.

13. Coile C, Gruber J. Future social security entitlements and the retirement decision. Rev Econ Stat. 2007;89(2):234-46. https://doi.org/10.1162/rest.89.2.234.

14. de Wind A, van der Pas S, Blatter BM, van der Beek AJ. A life course perspective on working beyond retirement: results from a longitudinal study in the Netherlands. BMC Public Health. 2016;16(1):1. https://doi.org/10.1186/s12889-016-3174-y

15. Hofäcker D, Naumann E. The emerging trend of work beyond retirement age in Germany. Z Gerontol Geriat. 2014:1-7.

16. Dingemans E, Henkens K, van Solinge H. Working Beyond Retirement in Europe: An Investigation of Individual and Societal Determinants Using Share. Netspar Discussion Paper. 2016; No. 06/2016-022.

17. Dingemans E, Henkens KA, van Solinge H. Access to Bridge Employment: Who Finds and Who Does Not Find Work After Retirement? Gerontologist. 2015:182. 
18. Ybema JF, Geuskens GA, van den Heuvel SG, de Wind A, Leijten FR, Joling CI, et al. Study on Transitions in Employment, Ability and Motivation (STREAM): The design of a four-year longitudinal cohort study among 15,118 persons aged 45 to 64 years. Br J Med Med Res 2014;4(6):1383-99. https://doi.org/10.9734/BJMMR/2014/7161

19. Centraal Bureau voor de Statistiek. Inkomen en bestedingen [Income and expenditure]. Den Haag: Centraal Bureau voor de Statistiek; 2016 [updated 2016; cited 2015 5/18/2015]. Available from: https://www.cbs.nl/nl-nl/onze-diensten/ maatwerk-en-microdata/microdata-zelf-onderzoek-doen/ catalogus-microdata/inkomen-en-bestedingen.

20. de Wind A, Geuskens GA, Ybema JF, Bongers PM, van der Beek AJ. The role of ability, motivation, and oppurtunity to work in the transition from work to early retirement - Testing and optimizing the Early Retirement Model. Scand J Work Environ Health. 2015;41(1):24-35. https://doi.org/10.5271/ sjweh.3468.

21. Royston P, Moons KG, Altman DG, Vergouwe Y. Prognosis and prognostic research: Developing a prognostic model. BMJ. 2009;338:b604. https://doi.org/10.1136/bmj.b604.

22. Ware JE, Kosinski M, Keller SD. SF-12: How to score the SF-12 physical and mental health summary scales: Health Institute, New England Medical Center; 1995.

23. Gandek B, Ware JE, Aaronson NK, Apolone G, Bjorner JB, Brazier JE, et al. Cross-Validation of Item Selection and Scoring for the SF-12 Health Survey in Nine Countries: Results from the IQOLA Project. J Clin Epidemiol. 1998;51(11):11718. https://doi.org/10.1016/S0895-4356(98)00109-7

24. Hertzog C, Van Alstine J, Usala PD, Hultsch DF, Dixon R. Measurement properties of the Center for Epidemiological Studies Depression Scale (CES-D) in older populations. Psychological Assessment. 1990;2(1):64. https://doi. org/10.1037/1040-3590.2.1.64.

25. Radloff LS. The CES-D scale a self-report depression scale for research in the general population. Appl Psychol Meas. 1977;1(3):385-401. https://doi. org/10.1177/014662167700100306.

26. Pearlin LI, Schooler C. The structure of coping. J Health Soc Behav. 1978:2-21. https://doi.org/10.2307/2136319.

27. Karasek R, Brisson C, Kawakami N, Houtman I, Bongers P, Amick B. The Job Content Questionnaire (JCQ): an instrument for internationally comparative assessments of psychosocial job characteristics. J Occup Health Psychol. 1998;3(4):322. https://doi.org/10.1037/1076-8998.3.4.322.
28. Dhondt S, Houtman I, Nelemans R. Handleiding NOVAWEBA: een vragenlijst om arbeidsorganisatorische knelpunten op te sporen: hernieuwde versie [Instructions NOVA-WEBA: a questionnaire to discover work-organizational bottlenecks: new version]. 2000 2000. Report No.

29. Kristensen TS, Hannerz H, HÃ A, Borg V. The Copenhagen Psychosocial Questionnaire: a tool for the assessment and improvement of the psychosocial work environment. Scand J Work Environ Health. 2005:438-49. https://doi.org/10.5271/ sjweh.948

30. De Boer EM, Bakker AB, Syroit JE, Schaufeli WB. Unfairness at work as a predictor of absenteeism. J Org Behav. 2002;23(2):181-97. https://doi.org/10.1002/job.135.

31. Visser M. Dwalingen in de methodologie. XXXIV. Predictiemodellen stellen vaak teleur [Errors in methodology. XXIV. Prediction models are often disappointing]. NTvG. 2001;145(23):1109-12.

32. McGarry K. Health and retirement do changes in health affect retirement expectations? J Hum Resour. 2004;39(3):624-48. https://doi.org/10.2307/3558990

33. Maestas N. Back to work: expectations and realizations of work after retirement. J Hum Resour. 2010;45(3):718-48. https://doi.org/10.3368/jhr.45.3.718.

34. Silventoinen K, Lahelma E, Rahkonen O. Social background, adult body-height and health. Int J Epidemiol 1999;28(5):9118. https://doi.org/10.1093/ije/28.5.911.

35. Maurits EEM, Veer AJEd, Francke AL. Werkdruk en werktevredenheid van belang voor kunnen doorwerken tot pensioen [Workload en job satisfaction are important for working until retirement]. Utrecht: 2012.

36. Chan ZC, Tam WS, Lung MK, Wong WY, Chau CW. A systematic literature review of nurse shortage and the intention to leave. J Nurs Manag. 2013;21(4):605-13. https://doi. org/10.1111/j.1365-2834.2012.01437.x.

37. Miilunpalo S, Vuori I, Oja P, Pasanen M, Urponen H. Selfrated health status as a health measure: the predictive value of self-reported health status on the use of physician services and on mortality in the working-age population. J Clin Epidemiol. 1997;50(5):517-28. https://doi.org/10.1016/ S0895-4356(97)00045-0.

Received for publication: 21 October 2016 